\title{
CD34 is not Expressed by Blasts in a Third of B-ALL Patients and Its Negativity is associated with Aberrant Marker Expression: A Retrospective Analysis
}

\author{
Neha Garg, Richa Gupta*, Mrinalini Kotru
}

\begin{abstract}
Background: CD34 antigen is expressed by early hematopoietic progenitor cells and acute leukemia cells. Its expression is associated with good prognosis in acute myeloid leukemia. Literature is sparse on its prognostic significance in B- acute lymphoblastic leukemia (B-ALL) especially from India. Hence the present study was undertaken to analyse the frequency of $C D 34$ expression in B-ALL in Indian patients and determine its prognostic significance by associating with other prognostic markers and aberrant antigen expression. Methods: Seventy-five B-ALL patients diagnosed by flow cytometry over a period of $31 / 2$ year were studied. Correlation of $C D 34$ expression was studied with gender, age, total leucocyte count (TLC), French-American-British (FAB) morphological type, immuno-phenotypic markers, cytogenetics and minimal residual disease. Differences between groups were evaluated using Student's T-test for quantitative data and Chi-square test/Fishers exact T-test for qualitative variables. P value $<0.05$ was considered significant. Results: CD34 was positive in $66.66 \%(50 / 75)$ cases while it was negative in rest $(33.33 \%$; $25 / 75)$ cases. $\mathrm{CD} 13, \mathrm{CD} 33, \mathrm{CD} 5, \mathrm{CD} 7$ and CD11b were more frequently expressed in CD34 negative B-ALL ( $\mathrm{p}=0.025$ ). No association of $C D 34$ expression was found with gender, age, TLC, FAB morphological type, other immune-phenotypic markers, MRD and cytogenetics studied. Conclusions: The expression of CD34 does not associate with known prognostic markers in B-ALL. However, absence of CD34 is associated with aberrant immunophenotypic expression (myeloid + T-cell antigens) in these patients. Larger studies with larger sample size and more extensive immunophenotypic panel needs to be done in Indian setup to confirm these findings.
\end{abstract}

Keywords: CD34- B- acute lymphoblastic leukemia- acute leukeimia, immunophenotype- flow cytometry- aberrant

Asian Pac J Cancer Prev, 22 (3), 919-925

\section{Introduction}

Acute lymphocytic leukemia (ALL) is the most common hematological malignancy in Indian children. With recent technological advances in the last decade, flow cytometric immunophenotyping on blood or bone marrow sample has become the most widely used technique for lineage determination in leukemias and establishing the diagnosis of B ALL. In addition, it is also used for MRD analysis which is considered the most important prognostic factor following chemotherapy. CD34, a marker of immaturity, is of paramount importance in this regard as it is used both in diagnosis as well as its pattern of expression helps to differentiate blasts from hematogones in a regenerative bone marrow $(\mathrm{BM})$ later.

CD34 is a transmembrane protein that was first identified on hematopoietic stem and progenitor cells. It promotes attachment of these progenitor cells to the components of stromal microenvironment thus promoting their growth and differentiation and mediates resistance to apoptosis. It is a marker of immaturity or blast population in B- acute lymphoblastic leukemia (B-ALL) which usually also express $C D 10$ (co-expressed in approximately $70 \%$ of common B-ALL) and lack CD20 (Basso et al.,2001). As the blasts mature, CD34 and CD10 antigens sequentially decrease in intensity and become negative while the intensity of $C D 20$ expression on the surface increases (Basso et al.,2001). However, a large percentage $(50 \%)$ of the phenotypically more immature $\mathrm{B}$ blasts that is the pre pre-BALL blasts are negative for both CD10 and CD34, thus accounting for those cases where $C D 34$ expression is absent (Basso et al.,2001). Yet, CD34 is universally used as one of the markers for blast identification in ALL panel. In the absence of an extensive panel with more markers which may not be available everywhere, there is a risk of missing the diagnosis with such an approach. Further, some studies have also assigned prognostic significance to $\mathrm{CD} 34$ as it is reported that the expression of $C D 34$ is associated with good prognosis in acute myeloid leukemia (Basso et al., 2001). However, 
literature is sparse on the prognostic significance of CD34 expression in B-ALL especially from India. Hence the present study was undertaken to analyse the frequency of CD34 expression in B-ALL in Indian patients and determine its prognostic significance by associating with other prognostic markers and aberrant antigen expression.

\section{Materials and Methods}

This is a retrospective analysis of data carried out in the Hematology section of Department of Pathology of a tertiary care hospital in Delhi, India over a period of three and a half years. Seventy-five cases diagnosed as B-ALL over these years were evaluated. Complete clinical history, physical examination, and investigations along with immunophenotypic details of these cases were noted from the records.

Complete blood cell count was done on Beckman coulter LH 500. Peripheral blood (PB) and bone marrow aspirate (BMA) smears were stained with Wright's stain.

Immunophenotye (IPT): IPT of blasts was done from lysed whole peripheral blood (PB) or bone marrow aspirate (BMA) (lyse and wash protocol) using flow cytometer (Beckman coulter cytomics FC 500) equipped with facility for at least 5-color IPT.

The panel used for characterisation of blasts was as follows: Immaturity markers: CD45/CD34/TdT/HLADR, myeloid markers: cMPO/CD117/CD13/CD33/CD64/ CD11b, T lymphoid markers: cCD3/CD3/CD5/CD7, B-lymphoid markers: CD79a/CD10/CD19/CD20.

A threshold of $20 \%$ was used to define a positive reaction of blast cells to a given monoclonal antibody, except for cMPO, cCD3, cCD79a and TdT, which were considered positive at $10 \%$ level of expression (Chiaretti et al., 2014). Patients were diagnosed as B-ALL on the basis of WHO criteria i.e. strong CD19 plus strong expression of at least one of CD79a, cCD22, CD10 or weak CD19 plus strong expression of at least two of $C D 79 a, c C D 22$, CD10 (Swerdlow et al., 2008).

Cytogenetics analysis: This was done by fluorescence in situ hybridisation (FISH) for $\mathrm{t}(9 ; 22), \mathrm{t}(12 ; 21), \mathrm{t}(4 ; 11)$ at the time of diagnosis. Data on cytogenetics was available for 24/75 cases.

Minimal residual disease (MRD): Cell preparation was done using stain-lyse-wash method on BMA sample using flow cytometer (Beckman coulter cytomics FC 500) equipped with facility for at least 5-color flow panel. Following markers were used: CD45, CD10, CD19, CD20, CD34, CD38, CD58, CD128, CD123, CD86 and CD200. A cut-off of $0.01 \%$ was used to define MRD positivity. Data on MRD was available for $25 / 75$ cases.

Statistical analysis was performed using MS EXCEL and SPSS software version 20. Numerical data were expressed as mean and standard error of mean. Qualitative data was expressed as frequency and percentage. Differences between groups were evaluated using Student's T-test for quantitative data and Chi-square test/ Fishers exact T-test for qualitative variables. $\mathrm{P}$ value less than 0.05 was considered significant.

\section{Results}

Clinico-hematological profile

Out of 75 cases of B-ALL diagnosed, 40 were males and 30 were females with a male to female ratio of 1.3 . There were 58 cases in the age group of 2-10 years with a mean \pm SD age of $4.75 \pm 1.9$ years and 17 cases in the age group of $>10$ years with a mean \pm SD age of $22.56 \pm 11.4$ years. Total leucocyte count ranged from 1.3 to $580 \times 10^{9} / \mathrm{L}$ with a median of $25 \times 10^{9} / \mathrm{L}$. The mean blast count was 56.6 .

Morphological (French-American-British [FAB]) subtype $41.4 \%(31 / 75)$ cases had FAB L1 morphology with presence of regular round homogenous blasts with only little clefting while $58.6 \%(44 / 75)$ cases had FAB L2 morphology with presence of heterogeneous blasts with moderate amount of cytoplasm, vacuoles, prominent nucleoli and prominent indentations and clefting. No case had L3 morphology.

\section{Immunophenotypic profile}

CD34 expression: CD34 was seen in blasts in $66.66 \%$ (50/75) cases. Figure 2 shows flow cytometry of a case of CD34 negative B-ALL. HLA DR proved to be more useful for defining immaturity as it was expressed by blasts in 92\% (69/75) cases.

Expression of B lineage markers: CD19 was expressed in all the 75 cases. The next most common B lineage antigen was cytoplasmic CD79a which was expressed in $96 \%$ followed by CD10 in $94.6 \%$ (Figure 1). Though blasts are immature cells, $66.6 \%$ showed a variable expression of $C D 20$ with asynchronous co-expression of CD34 and CD20 seen in $44 \%(33 / 75)$. So, according to the EGIL classification, there were $4(5.4 \%)$ cases of Pro-B-ALL or EGIL B-1 subtype [(A positive reaction for any two of CD19, CD22 (membrane and cytoplasm) and CD79a)

Table 1. Immunophenotypic Parameters According to CD34 Expression in B-ALL $(\mathrm{N}=75)$

\begin{tabular}{|c|c|c|c|}
\hline Parameter & $\begin{array}{l}\text { CD } 34 \text { Positive } \\
\quad(\mathrm{N}=50, \%)\end{array}$ & $\begin{array}{c}\text { CD } 34 \text { Negative } \\
(\mathrm{N}=25, \%)\end{array}$ & p-value \\
\hline \multicolumn{4}{|l|}{$\mathrm{CD} 10$} \\
\hline Negative & $02(4)$ & $02(8)$ & 0.407 \\
\hline Positive & $48(96)$ & $23(92)$ & \\
\hline \multicolumn{4}{|l|}{ CD 20} \\
\hline Negative & $17(34)$ & $08(32)$ & 0.538 \\
\hline Positive & $33(66)$ & $17(68)$ & \\
\hline \multicolumn{4}{|l|}{ HLADR } \\
\hline Negative & $04(8)$ & $02(8)$ & 0.685 \\
\hline Positive & $46(92)$ & $23(92)$ & \\
\hline \multicolumn{4}{|c|}{$\mathrm{CD} 13+\mathrm{CD} 33$} \\
\hline Negative & $42(84)$ & $16(64)$ & 0.051 \\
\hline Positive & $08(16)$ & $09(36)$ & \\
\hline \multicolumn{4}{|c|}{$\mathrm{CD} 13+\mathrm{CD} 33+\mathrm{CD} 5+\mathrm{CD} 7+\mathrm{CD} 11 \mathrm{~b}$} \\
\hline Negative & $37(74)$ & $12(48)$ & $.025^{*}$ \\
\hline Positive & $13(26)$ & $13(52)$ & \\
\hline
\end{tabular}


Table 2. Clinical and Laboratory Parameters According to $C D 34$ Expression in B-ALL $(\mathrm{N}=75)$

\begin{tabular}{lccc}
\hline Parameter & $\begin{array}{c}\text { CD 34 Positive } \\
(\mathrm{N}=50, \%)\end{array}$ & $\begin{array}{c}\text { CD 34 Negative } \\
(\mathrm{N}=25, \%)\end{array}$ & p-value \\
\hline Age & & & \\
2 -10 years & $39(78)$ & $19(76)$ & 0.531 \\
$>10$ years & $11(22)$ & $06(24)$ & \\
Sex & & & \\
Male & $27(54)$ & $16(64)$ & 0.283 \\
Female & $23(46)$ & $09(36)$ & \\
Total leucocyte count $/ \mathrm{mm}^{3}$ & & \\
$<50,000$ & $33(66)$ & $18(72)$ & 0.401 \\
$>50,000$ & $17(34)$ & $07(28)$ & \\
FAB type & & & \\
L1 & $20(40)$ & $11(44)$ & 0.465 \\
L2 & $30(60)$ & $14(56)$ & \\
MRD (N=25) & & & \\
Negative & $14(73.6)$ & $6(100)$ & 0.219 \\
Positive & $5(26.3)$ & $0(0)$ & \\
Cytogenetics $(\mathrm{N}=24)$ & & $5(100)$ & 0.479 \\
Negative & $16(84.2)$ & $0(0)$ & \\
Positive & $3(15.8)$ & & \\
\hline
\end{tabular}

FAB, French-American-British; MRD, Minimal residual disease

without further differentiation markers] and 71 (94.6\%) cases of CD10 positive B-ALL (EGIL B-2) subtype
(Chiaretti et al., 2014).

Aberrant marker expression: A total of $34.6 \%(26 / 75)$ cases exhibited aberrant expression of immunophenotypic markers. The most common aberrant marker expressed was CD33 seen in $14.6 \%(11 / 75)$ cases, followed by CD 7 and CD13 seen in $8 \%(6 / 75)$ cases each. CD5 was expressed in $4 \%(3 / 75)$ cases, and CD11b in $1.33 \%(1 / 75)$ cases.

Cytogenetics: Out of the 24 cases where data on cytogenetics was available, $3 / 24$ had a positive cytogenetic analysis at diagnosis. These were positive for $\mathrm{t}(9 ; 22)$, $\mathrm{t}(12 ; 21)$, and one was a known case of neurofibromatosis 1 (NF1).

Minimal residual disease: Data on MRD was available for $25 / 75$ cases. Out of these 25 , MRD was positive in $5 / 25,20 \%$ of cases. Out of these 5,2 had positive cytogenetics at diagnosis for NF1 and $t(9 ; 22)$.

Comparison between CD34 positive and negative group: The two groups were then compared with respect to aberrant marker expression and prognostic factors (Tables 1 and 2).

With respect to expression of one or more aberrant antigens, the CD34 negative group showed a significantly higher expression of one or more of the following - $C D 13$, CD33, CD5, CD7, and CD11b ( $\mathrm{p}=0.25)$ (Table 1).

Comparison of $C D 34$ expression and other prognostic parameters (Age, TLC, and MRD and Cytogenetics) (Table 2): The CD34 positive and negative group did not show any significant difference with respect to age, cytogenetics and FAB morphology. Though MRD and

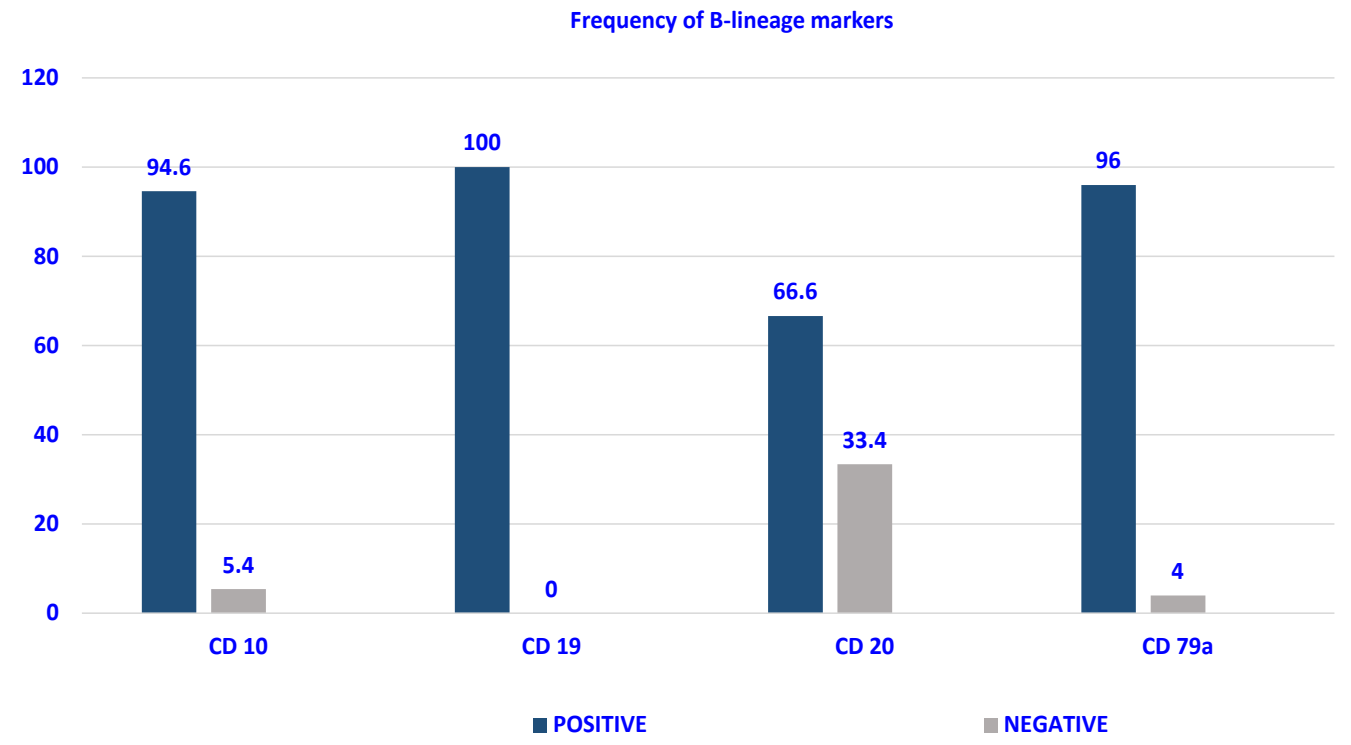

Figure 1. Frequency of B-lineage markers in B-ALL (\%) $(\mathrm{N}=75)$

Table 3. Comparison of Aberrant Antigen Expression in B-ALL in Indian Literature

\begin{tabular}{lccccc}
\hline Serial number & CD33 (\%) & CD13 (\%) & CD7 (\%) & CD5 (\%) & CD11b (\%) \\
\hline 1. Gujral et al (2009) & 6.07 & 2.78 & 0.9 & NA & NA \\
2. Birva et al (2019) & 14.0 & 15.0 & 0.0 & 0 & NA \\
3. Gupta et al (2019) & 17.9 & 25.6 & 0.03 & NA & NA \\
4. Sharma et al (2016) & 28.1 & 33.3 & 2.0 & NA & NA \\
5. Present study (2020) & 14.6 & 8.0 & 8.0 & 4 & 1.33 \\
\hline
\end{tabular}

NA, Not available 
Table 4. Comparison of Aberrant Myeloid Antigen Expression and CD34 Expression in ALL in Literature

\begin{tabular}{|c|c|c|c|c|c|c|}
\hline $\begin{array}{l}\text { Serial } \\
\text { number }\end{array}$ & Ethnicity & $\begin{array}{l}\text { Age group } \\
\text { (years) }\end{array}$ & $\begin{array}{l}\text { Number of } \\
\text { patients }\end{array}$ & MyAg studied & $\begin{array}{c}\text { Correlation between } \\
\text { MyAg and CD34 }\end{array}$ & p-value* \\
\hline $\begin{array}{l}\text { 1. Mi et al } \\
\text { (1999) }\end{array}$ & Chinese & Adult & 102 & NA & $\begin{array}{c}\text { Not found in ALL and } \\
\text { B-ALL }\end{array}$ & NA \\
\hline $\begin{array}{l}\text { 2. Yeneral et } \\
\text { al (2002) }\end{array}$ & Turkish & $\begin{array}{l}\text { Adult } \\
(14-62)\end{array}$ & 46 & CD13, CD33 & Not found in ALL & 0.06 \\
\hline $\begin{array}{l}\text { 3. Vitale et } \\
\text { al (2007) }\end{array}$ & $\begin{array}{l}\text { European } \\
\text { (Rome) }\end{array}$ & $\begin{array}{l}\text { Adult } \\
(14-60)\end{array}$ & 377 & CD13, CD33 & $\begin{array}{l}\text { Present between MyAg+ } \\
\text { and CD34+ in ALL }\end{array}$ & $<0.0001^{*}$ \\
\hline $\begin{array}{l}\text { 4. Tong et al } \\
(2010)\end{array}$ & Chinese & $\begin{array}{c}\text { All } \\
(1-72)\end{array}$ & 113 & $\begin{array}{l}\text { CD13, CD33, } \\
\text { CD15, CD117 }\end{array}$ & $\begin{array}{l}\text { Present between MyAg+ } \\
\text { and CD34+ in ALL }\end{array}$ & $0.002 *$ \\
\hline $\begin{array}{l}\text { 5. Tong et al } \\
(2011)\end{array}$ & Chinese & $\begin{array}{l}\text { Pediatric } \\
(0-14)\end{array}$ & 207 & $\begin{array}{l}\text { CD13, CD33, } \\
\text { CD15, CD117 }\end{array}$ & $\begin{array}{l}\text { Present between MyAg+ } \\
\text { and CD34+ in ALL }\end{array}$ & $0.004 *$ \\
\hline $\begin{array}{l}\text { 6. Tong et al } \\
\text { (2014) }\end{array}$ & Chinese & $\begin{array}{l}\text { Adult } \\
(15-77)\end{array}$ & 110 & $\begin{array}{l}\text { CD13, CD33, } \\
\text { CD15, CD117 }\end{array}$ & $\begin{array}{l}\text { Present between MyAg+ } \\
\text { and CD34+ in ALL }\end{array}$ & $0.019^{*}$ \\
\hline $\begin{array}{l}\text { 7. Sharma et } \\
\text { al (2014) }\end{array}$ & Indian & $\begin{array}{c}\text { All } \\
(2-61)\end{array}$ & $\begin{array}{l}\text { ALL (204) B- } \\
\text { ALL (163) }\end{array}$ & $\begin{array}{l}\text { CD13, CD33, } \\
\text { CD117 }\end{array}$ & $\begin{array}{c}\text { Present between MyAg+ } \\
\text { and CD34high in ALL and } \\
\text { B-ALL }\end{array}$ & $\begin{array}{l}0.0001 * \text { (in both } \\
\text { ALL and B-ALL) }\end{array}$ \\
\hline $\begin{array}{l}\text { 8. Sharma et } \\
\text { al (2016) }\end{array}$ & Indian & $\begin{array}{c}\text { All } \\
(<1-65)\end{array}$ & $\begin{array}{l}\text { Adult (96), } \\
\text { Pediatric } \\
\quad(207)\end{array}$ & $\begin{array}{l}\text { CD13, CD33, } \\
\text { CD117 }\end{array}$ & $\begin{array}{l}\text { Present between MyAg+ } \\
\text { and CD34+ in ALL }\end{array}$ & $\begin{array}{c}\mathrm{p}=0.001 *(\text { Adult }), \\
\mathrm{p}=0.0004 * \\
(\text { Pediatric })\end{array}$ \\
\hline $\begin{array}{l}\text { 9. Present } \\
\text { study }(2020)\end{array}$ & Indian & All & 75 & CD13, CD33 & Not found in B-ALL & 0.051 \\
\hline
\end{tabular}

NA, Not available; My, Myeloid antigen expression; My+, Myeloid antigen positivity; ALL, Acute lymphoblastic leukemia; B-ALL, B- acute lymphoblastic leukemia; ${ }^{*} \mathrm{p}<0.05$ is statistically significant
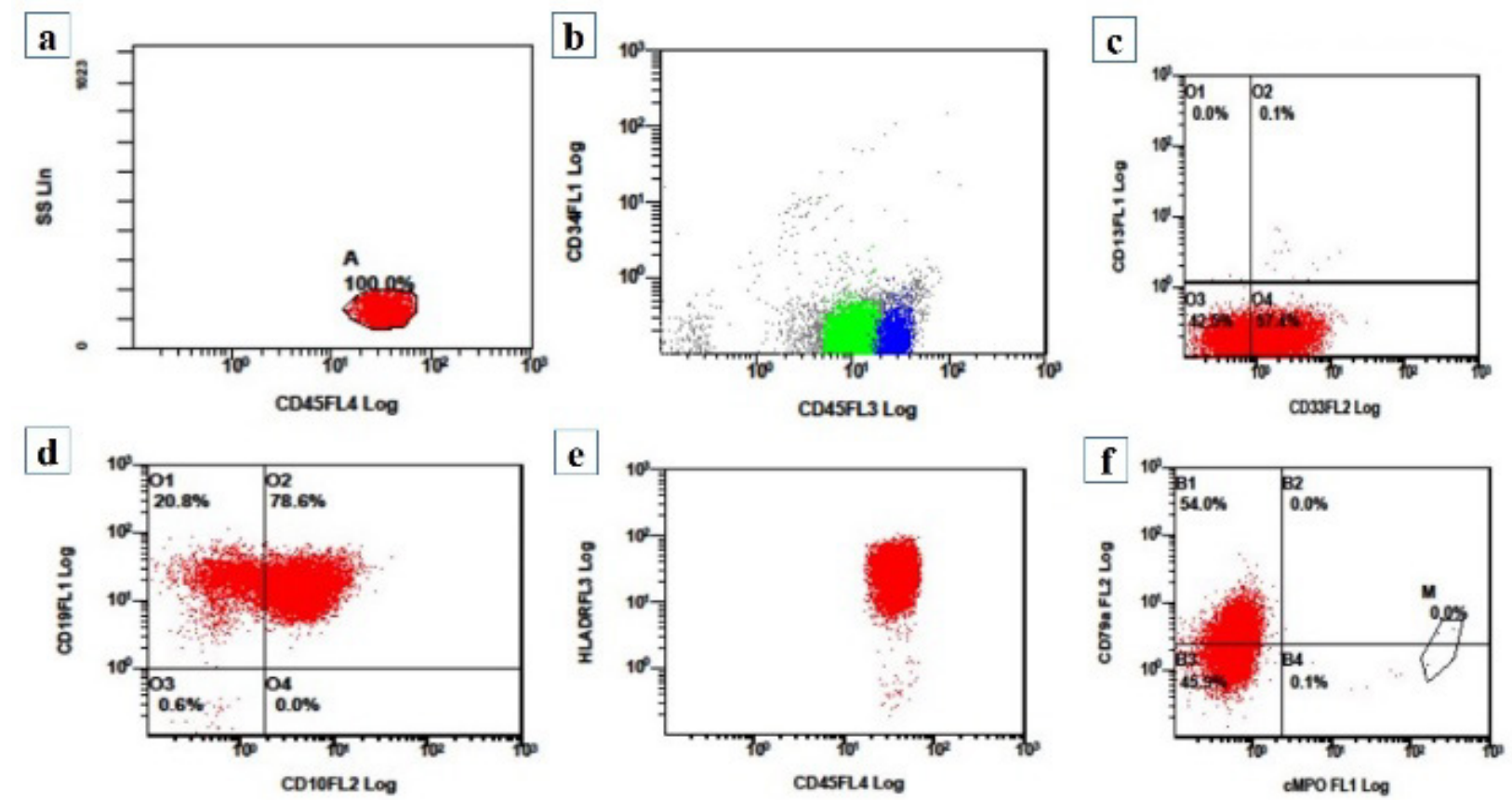

Figure 2. (a-f): Flow cytometry graphs of a case of CD34 negative B-ALL: (a) Side scatter on y-axis and CD45 on $\mathrm{x}$-axis shows a population of dim CD45 positive blasts. (b) CD 34 on y-axis and CD45 on x-axis shows CD34 negative blasts. (c) CD13 on $\mathrm{y}$-axis and CD33 on x-axis shows blast population heterogeneous positive for CD33 while negative for CD13. (d) CD19 on y-axis and CD10 on x-axis show all blasts expressing CD19 while being heterogeneous positive for CD10. (e) HLA-DR on $y$-axis and CD45 on x-axis shows HLADR positive blasts. (f) CD79a on y-axis and cMPO on $\mathrm{x}$-axis shows CD79a positive blasts while negative for myeloid marker cMPO. 
Cytogenetics were done only in limited number of cases, it was seen that CD34 negativity was not associated with adverse prognosis with respect to MRD or cytogenetics.

\section{Discussion}

The diagnosis and classification of acute leukemia is currently a multistep procedure based on morphology, immunophenotype, cytogenetics and molecular genetics. Flow cytometry immunophenotyping is extensively used in the diagnosis of almost all hematolymphoid neoplasms because of its capacity to analyse multiple markers simultaneously on the same cells and rapid results.

Diagnosis of B ALL is based on lineage assignment (A strong CD19 plus strong expression of at least one of $C D 79 a, c C D 22, C D 10$ or weak $C D 19$ plus strong expression of at least two of CD79a, cCD22, CD10) and expression of immaturity markers by the atypical cell population (Chiaretti et al., 2014). CD34, an immaturity marker, usually expressed in leukemia cells is universally used as it unequivocally establishes the immature nature of these cells. However, several studies from the West and some Indian studies have documented that CD34 may not be uniformly expressed in all cases of B ALL. Literature is sparse on the expression of $C D 34$ expression in $\mathrm{B}-\mathrm{ALL}$ from India, as well as its prognostic significance is not well explored. Hence the present study was undertaken to analyse the frequency of $C D 34$ expression and its association with other prognostic markers in B-ALL patients from a tertiary care centre in India.

The frequency of CD34 positivity in B-ALL was $66.6 \%$ while $33.3 \%$ did not express CD34. The reported frequency of CD34 in B-ALL from previous Indian studies ranges from 30\%-81.3\% (Gujral et al., 2009; Sharma et al., 2016; Birva et al., 2019; Gupta et al., 2019) and in studies from other parts of the world is also in similar range of $47.8 \%$ to $83 \%$ (Thalhammer-Scherrer at al., 2002; Dakka et al., 2009; Jaafar et al., 2018; Rezaei et al., 2020). As regards immaturity we found HLA-DR better for delineation of blasts as its expression was seen in $92 \%$ cases. The reported frequency of HLA-DR in $\mathrm{B}-\mathrm{ALL}$ from previous Indian studies is also higher than CD34 expression in B-ALL ranging from 97.4\%-100\% indicating that it's a better marker of immaturity (Gujral et al., 2009; Birva et al., 2019; Gupta et al., 2019).

There were $5.7 \%$ cases of pro-B-ALL and $94.2 \%$ cases of CD10 positive B-ALL. CD19 expression in $100 \%$ of cases and CD79a was positive in $96 \%$ cases. Our results are similar to Indian study by Gujral et al., (2009) who found $96 \%$ CALLA positive B-ALL, 4\% pro-B-ALL, CD19 expression in $100 \%$ B-ALL cases. However, the expression of $C D 79 a(99.4 \%)$ was higher than the present study.

Asynchronous co-expression of CD34 and CD20 was seen in 44\% (33/75) (Table 1) cases. Seegmiller (2009) also reported such an asynchronous expression in $37.5 \%$ (75/200) cases of B-ALL cases while Sharma (2016) and Jalal (2017) an asynchronous dual expression of $C D 34$ and CD20 in 12\% cases. Firstly, such asynchronous expression of early and late antigens defies normal antigenic evolution of B-cell precursors and thus can be useful to differentiate blasts from hematogones in evaluating MRD. Secondly, CD20 expression is associated with poor prognosis in B-ALL (Thomas et al., 2009). However, introduction of anti-CD20 monoclonal antibody like rituximab to the traditional chemotherapy regimens can improve the survival outcomes in precursor B-ALL patients (Thomas et al., 2009).

There was a predominance of L2 morphology than L1 morphology in B-ALL blasts in the present study. Our findings are in contrast to previous studies who found L1 to be more common than L2 morphology in B-ALL (Bennett et al., 1981).

Aberrant expression is defined as presence of an antigen belonging to some other lineage. This is a well-known phenomenon in leukemias and helps in identification of the malignant cells/blasts. Further, some studies have documented that aberrant expression of myeloid antigens (CD13 and $C D 33)$ is associated with better prognosis while that of T-cell antigens (CD5 and CD7) is associated with worse prognosis in B-ALL (Hussein et al., 2011; Ibrahim et al., 2017). In the present study, out of the total 75 cases, 26 showed expression of aberrant markers. The most common aberrant marker expressed in the present study was CD33 seen in $14.6 \%$ cases, followed by CD 7 and CD13 each seen in $8 \%$ cases. Most of the Indian studies have found CD13 to be the most common aberrant marker expressed in B ALL followed by CD33 (Table 3). Table 3 shows the aberrant expression of various markers in B-ALL in Indian literature.

In this study, a significant association was seen between CD 34 negative B-ALL and expression of one or more aberrant immunophenotypic markers (CD13 + $\mathrm{CD} 33+\mathrm{CD} 5+\mathrm{CD} 7+\mathrm{CD} 11 \mathrm{~b})(\mathrm{p}=0.025)$ (Table 1). In a study by Jung (1996), there was a strong correlation between CD 34 negative ALL and aberrant expression of $C D 7$ and $C D 5$ only but not myeloid markers. $(\mathrm{p}=0.0005$, $\mathrm{p}=0.034$ respectively). Further, we found absence of $C D 34$ expression to be associated with a more frequent expression of myeloid markers $(C D 13+C D 33)$ though the results were not statistically significant $(p=0.051$, Table 1). This finding is similar to that found by Mi (1999) and Yeneral (2002) who did not find any relationship between myeloid antigen expression and CD34 positivity in both ALL, subgroup B-ALL and only ALL patients respectively (Table 4). However, other studies found a correlation (Table 4) (Vitale et al., 2007; Tong et al., 2010; Tong et al., 2011; Tong et al., 2014; Sharma eta 1., 2014; Sharma et al., 2016). These differences may be due to difference in demographics (ethnicity, age group studied), sample size, patient cohort (ALL instead of B-ALL) and myeloid antigens analysed. Table 4 shows the comparative analysis of aberrant myeloid antigen expression and CD34 expression in ALL in literature.

Absence of CD34 has been considered to be an independent adverse prognostic factor in B-ALL (Basso et al., 2011). CD34 positivity in B-ALL has been found to correlate with good prognostic factors like age 1-10 years, low TLC count and expression of CD10, CD19, HLADR in various studies (Basso et al., 2001; Dakka et al., 2009). Therefore, an attempt was made to correlate CD34 negativity with other prognostic factors. There 
was no association between CD34 negativity with age, sex, TLC and expression of CD10, HLADR (Table $1,2)$. Such a difference could be because of different sociodemographic profile and biology of B-ALL in Indian patients. Cytogenetics and MRD was available in only one third of the cases. CD34 negativity was not found to associate with bad cytogenetics or MRD positivity in these cases (Table 2). These findings are in contrast to the findings of studies form other countries as CD34+ is reported to be associated with $\mathrm{t}(12 ; 21]$, adults with $\mathrm{t}(9$; $22)$ and $t(4 ; 11)$ in B-ALL while CD34- is associated with $\mathrm{t}(1 ; 19)$ (Basso et al., 2001). These differences could also be because of availability of smaller number of patients with a cytogenetic test. As India being a developing nation, not all patients are able to afford these costly cytogenetic analytic tests.

To conclude, the expression of CD34 is not associated with other prognostic markers in B-ALL while absence of CD34 is associated with aberrant immunophenotypic expression of markers (myeloid $+\mathrm{T}$-cell antigens) in B-ALL. This may be due to the different sociodemographic profile and biology of the disease in Indian patients. Larger studies with larger sample size, more extensive immunophenotypic panel, cytogenetics and follow up survival analysis needs to be done in Indian setup to clearly understand the biology of expression of CD34 in B-ALL and thus paves the way for future research.

\section{Author Contribution Statement}

Literature search, data acquisition, data analysis, manuscript preparation and manuscript editing was done by NG. Concept, design of the study along with manuscript editing and review was done by RG. Manuscript editing and review was done by $\mathrm{MK}$.

\section{Acknowledgements}

\section{Scientific body approval and Ethical statement}

The research was approved by Research project approval committee and the Institutional Ethics Committee for Human Research (IEC-HR) of University college of Medical sciences and Guru Teg Bahadur hospital, Delhi, India and there were no ethical issues.

\section{Conflict of interest}

This is our original work and there is no conflict of interest.

\section{References}

Basso G, Lanza F, Orfao A, et al (2001). Clinical and biological significance of CD34 expression in acute leukemia. $J$ Biol Regul Homeos Agents, 15, 68-78.

Bennett JM, Catovsky D, Daniel MT, et al (1981). The morphological classification of acute lymphoblastic leukaemia: concordance among observers and clinical correlations. Br J Hematol, 47, 553-61.

Birva R, Hemangini V, Pina T, Biren P (2019). Flowcytometric analysis of leukemic blasts - as primary screening test for $\mathrm{BCR} / \mathrm{ABL} 1$ gene rearrangement in B- ALL. Eurasian J Med Oncol, 3, 191-8.
Chiaretti S, Zini G, Bassan R (2014) Diagnosis and subclassification of acute lymphoblastic leukemia. Mediterr J Hematol Infect Dis, 6, e2014073.

Dakka N, Bellaoui H, Bouzid N, et al (2009). CD10 AND CD34 expression in childhood acute lymphoblastic leukemia in Morocco: clinical relevance and outcome. Pediatr Hematol Oncol, 26, 216-31.

Gujral S, Badrinath Y, Kumar A, et al (2009). Immunophenotypic profile of acute leukemia: Critical analysis and insights gained at a tertiary care center in India. Cytometry B Clin Cytom, 76, 199-205.

Gupta N., Pawar R., Banerjee S, et al (2019). Spectrum and immunophenotypic profile of acute leukemia: a tertiary center flow cytometry experience. Mediterr J Hematol Infect Dis, 11, e2019017.

Hussein S, Gill KZ, Sireci AN, et al (2011). Aberrant T-cell antigen expression in B lymphoblastic leukaemia. $\mathrm{Br} J$ Haematol, 155, 449-56.

Ibrahim AM, Hameed BM (2017). Prognostic value of myeloid antigens expression in childhood acute lymphoblastic leukemia. Iraqi J Hematol, 6, 12-6.

Jaafar FH, Kadhom AE (2018). Expression of CD45, CD34, CD10, and human leukocyte antigen-DR in acute lymphoblastic leukemia. Iraqi $J$ Hematol, 7, 14-9.

Jalal SD, Al-Allawi NAS, Al Doski AAS (2017). Immunophenotypic aberrancies in acute lymphoblastic leukemia from 282 Iraqi patients. Int J Lab Hem, 00, 1-8.

Jung YS, Choi HS, Song KE, Lee WK, Kim JS (1996). Significance of CD34 expression in acute lymphoblastic leukemia. Korean J Clin Pathol, 16, 796-803.

Mi Y, Bian S, Chen G (1999). Study on the expression of myeloid markers an CD34 antigen in adult acute lymphoblastic leukemia. Zhonghua Xue Ye Xue Za Zhi, 20, 76-8.

Rezaei M, Refoua S, Esfandiari N (2020). Characterization of immunophenotypic aberrancies in adult and childhood acute lymphoblastic leukemia: Lessons from Regional Variation. Iran J Pathol, 15, 1-7.

Seegmiller AC, Kroft SH, Karandikar NJ, McKenna RW (2009). Characterization of immunophenotypic aberrancies in 200 cases of B acute lymphoblastic leukemia. Am J Clin Pathol, 132, 940-9.

Sharma RK, Purohit A, Somasundaram V, et al (2014). Aberrant myeloid antigen co-expression is correlated with high percentages of CD34-positive cells among blasts of acute lymphoblastic leukemia patients: an Indian tertiary care center perspective. Blood Res, 49, 241-5.

Sharma M, Sachdeva MU, Varma N, Varma S, Marwaha RK (2016). Characterization of immunophenotypic aberrancies in adult and childhood acute lymphoblastic leukemia: A study from Northern India. J Can Res Ther, 12, 620-6.

Thalhammer-Scherrer R, Mitterbauer G, Simonitsch I, et al (2002). The immunophenotype of 325 adult acute leukemias: Relationship to morphologic and molecular classification and proposal for a minimal screening program highly predictive for lineage discrimination. Am J Clin Pathol, 117, 380-9.

Thomas DA, O'Brien S, Jorgensen JL, et al (2009). Prognostic significance of CD20 expression in adults with de novo precursor B-lineage acute lymphoblastic leukemia. Blood, 113, 6330-7.

Tong H, Zhang J, Lu C, Liu Z, Zheng Y (2010). Immunophenotypic, cytogenetic and clinical features of 113 acute lymphoblastic leukaemia patients in China. Ann Acad Med Singapore, 39, 49-53.

Tong H, Wang Q, Lu C, Liu Z, Hu Y (2011). Immunophenotypic, cytogenetic, and clinical features of 207 cases of childhood acute lymphoblastic leukemia in china. $J$ Pediatr Hematol Oncol, 33, 437-41. 
Tong H, Wang H, Wang Q, Liu Z, Lu C (2014). Immunophenotypic, cytogenetic and clinical features in Chinese adult acute lymphoblastic leukaemia (ALL) patients. Ann Acad Med Singapore, 43, 152-9.

Vitale A, Guarini A, Ariola C, et al (2007). Absence of prognostic impact of CD13 and/or CD33 antigen expression in adult acute lymphoblastic leukemia. Results of the GIMEMAALL 0496 trial. Haematologica, 92, 342-8.

Yenerel MN, Atamer T, Yavuz AS, et al (2002). Myeloid antigen expression provides favorable outcome in patients with adult acute lymphoblastic leukemia: a single-center study. Ann Hematol, 81, 498-503.

\section{(c) (1) 8)}

This work is licensed under a Creative Commons AttributionNon Commercial 4.0 International License. 